\title{
Infection control perception and behavior: a question of sex and gender? Results of the $\mathrm{AHOI}$ feasibility study
}

This article was published in the following Dove Press journal: Infection and Drug Resistance

\author{
Tillmann Goerig' \\ Kathleen Dittmann' \\ Axel Kramer' \\ Stephan Diedrich ${ }^{2}$ \\ Claus-Dieter Heidecke ${ }^{2}$ \\ Nils-Olaf Huebner' \\ 'Institute of Hygiene and \\ Environmental Medicine, \\ Universitätsmedizin Greifswald, \\ Greifswald, Germany; ${ }^{2}$ Department \\ of General Surgery, Visceral, \\ Thoracic and Vascular Surgery, \\ Universitätsmedizin Greifswald, \\ Greifswald, Germany
}

Purpose: Infections, in particular with multidrug-resistant organisms, are a burden for inpatient and outpatient care and the whole community. The pathogens "roam" with patients and their relatives, forming an epidemiological bridge between different care facilities. Patients could play an important role in infection control, given that they are properly involved. The AHOI project stands for the Activation of patients, people in need of care, and care-providers for a Hygieneconscious participatiOn in Infection prevention. To this end, a multimodal intervention bundle was developed and subjected to a feasibility study at a university hospital. Our goal was to clarify whether sex- and gender-specific characteristics are relevant in the field of infection prevention. Materials and methods: AHOI was tested with a cross-sectional design and a cross-media communication strategy at two surgical wards of a university hospital. Interventions included patient information brochures and motivational materials, reminders, and two video presentations. A welcome box with information material and two questionnaires was given to every inpatient. The patients were instructed to complete the questionnaires at the beginning and at the end of their stay.

Results: A sample size of 133 inpatients who completed questionnaires at the beginning and end of hospitalization was analyzable. The analysis produced a differentiated picture of the perception and reaction behavior of the sexes. Women had a more negative expectation of the response of doctors. In addition, there were differences in the perception of the positioning of disinfectant dispensers and cleaning processes as well as in satisfaction with the general cleanliness. For all subjects mentioned above, the differences were significant at least at the $P$-value 0.05 .

Conclusion: The AHOI study shows sex differences in hygiene perception and behavior. Measures to improve patient safety by involving patients in infection control must take these differences into account.

Keywords: cross infection, prevention and control, disease transmission, hand hygiene, health communication, health education

\section{Introduction}

In Europe, about 2.5 million life years are lost each year due to immediate or longterm consequences of hospital-acquired infection. ${ }^{1}$ Infections with multidrug-resistant organisms are of particular concern. This development is not only limited to hospitals but also includes medical practices, inpatient and outpatient care, as well the community. The pathogens "roam" with patients, creating an epidemiological bridge between hospitals and other care facilities. ${ }^{2}$ Therefore, these patients could play an important role in preventing nosocomial infection and transmissions. However, several studies detected gaps in the hygiene behavior of these groups. ${ }^{3,4}$ This shows that there is a great
Correspondence: Tillmann Goerig and Environmenta Walther-Rathenau-Straße 49a, 17475

Greifswald, Germany

Tel +4938345I5598

Fax +49383451559l

Email tillmann.goerig@uni-greifswald.de 
need for solutions to prevent nosocomial infections and the opportunity to optimize the infection prevention. Especially in the field of education and involvement of patients, their relatives, and visitors, pioneering work is required..$^{5} \mathrm{AOI}$ is intended to close this gap in patient safety. The AHOI project stands for the Activation of patients, people in need of care, and care-providers for a Hygiene-conscious participatiOn in Infection prevention. Initially, a feasibility study was conducted to test the implementation of the intervention under real-world conditions. An important aspect of implementing prevention attempts is the sex of a patient. The sex of a person can be an important factor in the inclusion of patients and people in need of care in prevention and treatment. Therefore, the influence of sex is an important area of interest for medical research, but has so far been given little consideration in the context of infection prevention. ${ }^{6,7}$ Based on sex-based differences, it can be assumed that there is a difference in the perception, evaluation, and implementation of infection control conditions, deficiencies, and rules between the sexes. To enable a review of this assumption and seek a use for the AHOI approach, data were collected in a feasibility study. From this follows the question as to whether there is a sex difference in perception and reception of hygiene conditions, deficiencies and rules, and if so, whether sex differences should be taken into account by AHOI intervention materials.

\section{Material and methods Study design and ethics commission}

The AHOI project study was carried out in cooperation with the Institute of Hygiene and Environmental Medicine, the Department of General Surgery, Visceral, Thoracic and Vascular Surgery of University Medicine Greifswald and the Chair of General Business Administration and Health Care Management of the University of Greifswald. AHOI was tested with a cross-sectional design and a cross-media communication strategy.

A complex intervention with implementation of patient safety codes, surveys, and participation of patients and visitors in infection prevention was developed. The AHOI materials included patient information brochures and motivational materials, reminders, and two video presentations for patients. Furthermore, an integrative AHOI workshop was held for the hospital staff. The instruments were implemented on two surgical wards in a third-level university hospital as part of a feasibility study. Further, a noncontact disinfectant dispenser was installed in the main waiting area in addition to a dispenser already present in the adjacent hospital cafeteria. Both devices were mounted in places rather peripheral to surfaces in constant use. The study was conducted from 26 January to 3 May 2017. Every adult patient (minimum 18 years old) was invited to participate in the survey. Participation was strictly voluntary. Patients were informed by members of the AHOI team and by a cover letter about the anonymous nature of the study. The returned questionnaires, in a closed envelope, were therefore deemed to be informed consent.

This study was approved by the Medical Ethics Committee of the University Medicine Greifswald (BB 087/16b). A total of 310 AHOI boxes with 620 questionnaires were handed out. There were two questionnaires for every patient in one box, one to be filled out upon admission to the hospital and the other upon discharge.

\section{Data collection}

The admission-questionnaire included questions about the demographic data and general hygiene behavior of the patients. The discharge-questionnaire requested the perception and implementation of hygiene. Assessment of sexspecific differences was deliberately taken into account in the questionnaires design to enable possible sex-specific optimization of the interventions. The question was "Which gender are you?" with the answer options "male" and "female." Please note, that this survey was conducted in Germany and the original question in German was "Welches Geschlecht haben Sie?". The German word "Geschlecht” implies several meanings, including "biological sex" and "gender."

As far as possible, the items were constructed as closed questions with a nominal or ordinal scale ("yes-no"; or a ten-step scale: "negative-positive"; or a four-point scale: "almost always," "often," "occasional," and "hardly"). Age was recorded on a six-point scale $(1=18-20$ years, $2=21-30$ years, $3=31-45$ years, $4=46-60$ years, $5=61-70$ years, $6=$ over 70 years). In addition, the questionnaires include mainly halfopen questions and a few open questions to allow specific answers. This way, without predefined answer options, the respondents were asked for their vocational training and their current job. Participation was voluntary and anonymous. The questionnaires were personally handed out to the patients with the AHOI information box when admitted to the wards.

\section{Processing and data analyses}

The survey was converted into an active PDF form (Adobe Acrobat XI) and consolidated using built-in functions of Adobe Acrobat and exported to SPSS. IBM SPSS Statistics 22 (Version 22.0; IBM Corporation, Armonk, NY, USA) was used for statistical analysis. 
The analysis was carried out primarily with regard to sex-related differences. At the same time, other demographic factors that could influence the perception and handling of hygiene were evaluated. The requested vocational training and job data of the respondents were categorized into dichotomous characteristics of the categories "occupational training with extended hygiene knowledge" and "job with extended hygiene knowledge" for an additional criterion. Professionals with a broader level of hygiene-related knowledge were categorized as having a clear awareness of and need for correct hygiene behavior and pertinent experience during their education. Consequently, persons with veterinary, nursing, or pharmaceutical training were assessed as having advanced hygiene skills. Experience as medical assistant or medical technical assistant was also assumed to be related to greater knowledge of hygiene. Under the same conditions, the answers to the question "What is your current job?" were also categorized. In addition to the data already recorded for the occupational sector, further information was categorized as relevant to hygiene. People working as cleaning staff or medical device consultants were classified as having extended hygiene awareness. Respondents who had a hygiene-relevant education but identified themselves as retired were considered as persons without extended hygiene knowledge for categorization purposes. This conservative interpretation was used because the time point of the individual's training or education could not be determined.

A $P$-value of 0.05 was always used as a confidence benchmark and was used in all data analyses in this study. In addition to the mean comparisons and risk ratio calculations, correlation tests such as the chi-squared test, Lambda, Cramér's-V, and Goodman-Kruskal-Tau were performed. For all inferential statistics, robustness tests were carried out, ie, Bootstrapping and ANOVA. All presented percentages are rounded to the first place after the decimal point.

\section{Results}

\section{Response rate and description of sample}

A total of 310 information boxes including 310 admission questionnaires and 310 discharge questionnaires were dispensed to patients. In total, 179 admission questionnaires (return rate: $57.7 \%$ ) and 139 discharge questionnaires (return rate: $44.8 \%$ ) were returned and evaluable. From these questionnaires, 266 were answered from an individual patient on both survey dates, which means that 133 patients filled out their two questionnaires (overall return rate: $133 / 310=42.9 \%$ ). Of the respondents, 64 were men (48.1\%) and 67 were women (50.4\%). Two patients did not specify their sex. The average age group according to the six-point scale was 4.26 (median 4.00, SD 1.28). The category 4 indicates the age group of 46-60 years. The demographic data on age and education did not show statistically significant differences between the sexes (Table 1). The distribution of age is shown in Figure 1. The average length of hospital stay of the female patients was 5.33 days (d) (total length average $6.30 \mathrm{~d}$, median $4 \mathrm{~d}$, SD $5.44 \mathrm{~d}$ ), which tended to be higher in men $(7.19 \mathrm{~d})$. For the question "How often did you use the disinfection dispensers?" no statistically significant correlation for the sexes was found.

\section{Reception of hygiene conditions and rules}

In central areas, women perceived a lack of disinfection dispensers more often than did men. The question "Was it possible for you to disinfect your hands? - in the entrance area of the hospital" was answered significantly more often negatively by women than by men (risk ratio [RR]: 8.357 [95\% CI: 1.096-63.709], $P=0.017)$. A total of $16.1 \%$ of women $(9 / 56)$ and $1.9 \%$ of men (1/52) responded with "no." In other words, women had a 7.36-fold increased chance to

Table I Characteristics of the study population and analysis of the professional background, perception, evaluation, and expectation of hygiene-relevant factors by sex

\begin{tabular}{|c|c|c|c|c|}
\hline \multicolumn{2}{|c|}{ Mean values } & \multirow[b]{2}{*}{$P$-value } & \multirow[b]{2}{*}{$\begin{array}{l}\text { Risk ratio/ } \\
\text { mean } \\
\text { difference }\end{array}$} & \multirow[b]{2}{*}{$95 \% \mathrm{Cl}$} \\
\hline $\begin{array}{l}\text { Female } \\
\text { (n) }\end{array}$ & Male (n) & & & \\
\hline \multicolumn{5}{|c|}{ Age (6 groups) } \\
\hline $4.23(67)$ & $4.27(64)$ & 0.905 & - & - \\
\hline \multicolumn{5}{|c|}{ Education (4 groups) } \\
\hline $2.16(56)$ & $2.18(50)$ & 0.894 & - & - \\
\hline \multicolumn{5}{|c|}{ Length of stay (in days) } \\
\hline $5.33^{\mathrm{a}}(60)$ & $6.64^{\mathrm{a}}(58)$ & $0.121^{\mathrm{a}}$ & - & - \\
\hline \multicolumn{5}{|c|}{$\begin{array}{l}\text { Occupational training with extended hygiene knowledge } \\
\text { (I=yes, } 2=\text { no) }\end{array}$} \\
\hline $\mathrm{I} .76(54)$ & $1.97(63)$ & 0.001 & 7.583 & $1.790-32.124$ \\
\hline \multicolumn{5}{|c|}{ Perception disinfection entrance area ( $I=y e s, 2=$ no $)$} \\
\hline $1.16(56)$ & $\mathrm{I} .02(52)$ & 0.017 & 8.357 & $1.096-63.709$ \\
\hline \multicolumn{5}{|c|}{ Perception disinfection cafeteria ( $\mathrm{I}=$ yes, $2=$ no) } \\
\hline $1.22(36)$ & $1.05(43)$ & 0.037 & 4.778 & $1.082-21.091$ \\
\hline \multicolumn{5}{|c|}{ Perception daily cleaning door handle ( $I=y e s, 2=n o)$} \\
\hline $\mathrm{I} .48(47)$ & $1.21(48)$ & 0.009 & 2.247 & $1.197-4.219$ \\
\hline \multicolumn{5}{|c|}{ Satisfaction cleanliness sanitary facilities ( $1=y e s, 2=$ no) } \\
\hline $1.18(58)$ & $1.04(56)$ & 0.029 & 4.828 & $1.107-21.062$ \\
\hline \multicolumn{5}{|c|}{$\begin{array}{l}\text { Expected physician responses feedback ( } I=\text { negative- } \\
10=\text { positive) }\end{array}$} \\
\hline $6.06(64)$ & $7.43(6 I)$ & 0.004 & 1.364 & $0.45 \mathrm{I}-2.277$ \\
\hline
\end{tabular}

Note: a ${ }^{O}$ ne male outlier (39 days) removed. 


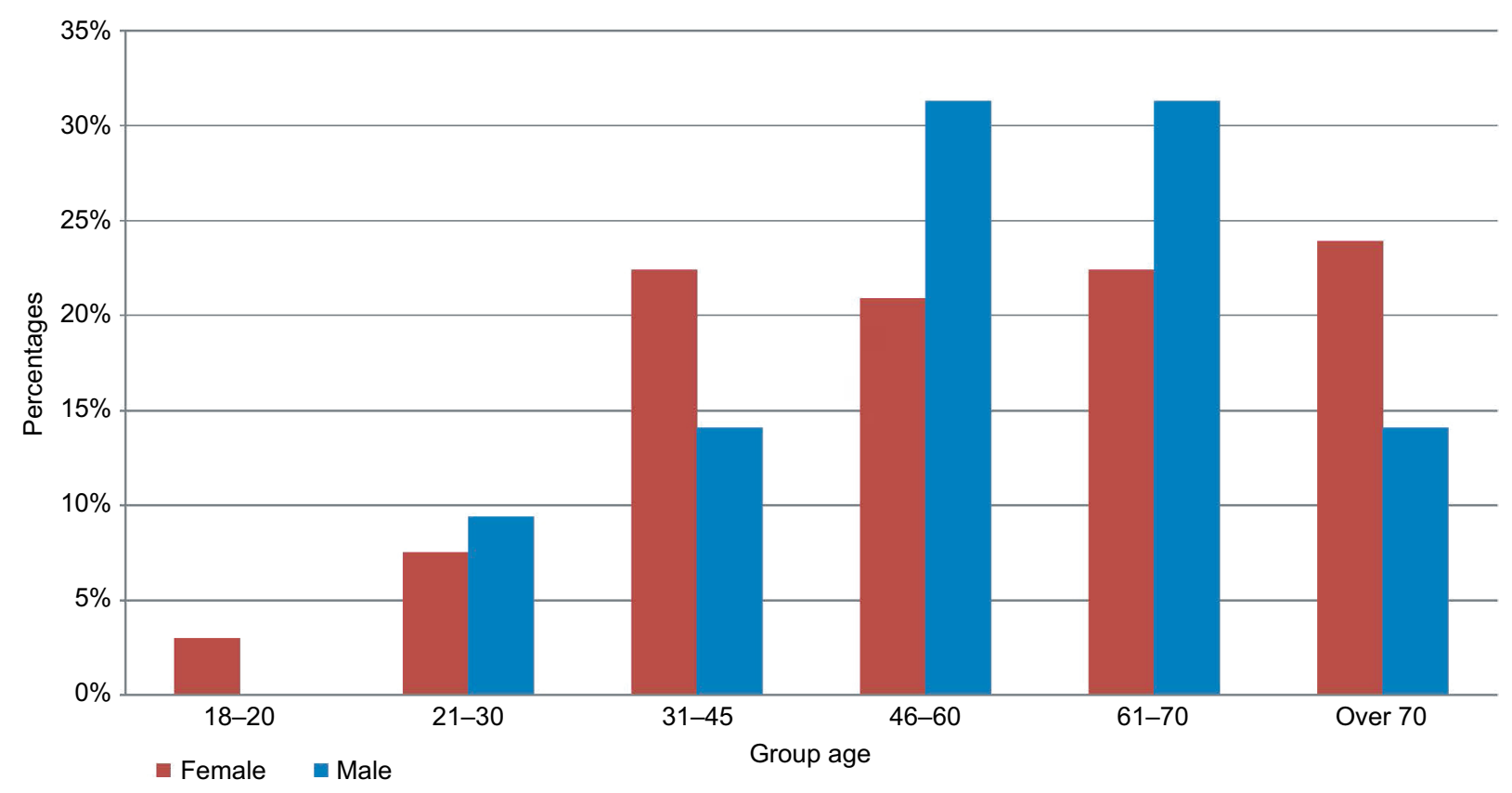

Figure I Distribution of age of the AHOI patients by groups ( $18-20$ years, $2 \mathrm{I}-30$ years, $3 \mathrm{I}-45$ years, $45-60$ years, $6 \mathrm{I}-70$ years, and $>70$ years old). Notes: Red=female, blue $=$ male. Number of females $=67 / 67$ and number of males $=64 / 64$.

perceive an actual lack of dispensers. This result was also evident in the question of disinfection opportunities in the area of the hospital cafeteria. Here, too, the female respondents perceived the opportunity for disinfection statistically significantly less often than did the male patients (RR: 4.778 [95\% CI: 1.082-21.091], $P=0.037)$. On the question "Was it possible for you to disinfect your hands? - in the cafeteria area of the hospital," $22.2 \%$ of women (8/36) and $4.7 \%$ of men (2/43) responded with "no" (Table 1). Women had a 3.78-fold increased chance to perceive a lack of dispensers. For the question "Was it possible for you to disinfect your hands? - in the waiting area of the hospital," the results weren't statistically significant.

However, the performance of the daily maintenance cleaning was evaluated by female respondents much more critically than by male patients. To the question "Were the doorknobs wiped daily with disinfectant by the cleaning staff?" surveyed women answered significantly more often with "no" than did men (RR: 2.247 [95\% CI: 1.197-4.219], $P=0.009)$. A total of $46.8 \%$ of women (22/47) and $20.8 \%$ of men (10/48) answered this question with "no" (Table 1). In other words, women had a 1.25 -fold increased chance to perceive a lack of cleaning. The cleaning result of the sanitary area was rated negative significantly more often by the female respondents than by the male patients (RR: 4.828 [95\% CI: $1.107-21.062$ ], $P=0.029)$. Ten of 58 women
$(17.2 \%)$ and two men out of $56(3.6 \%)$ answered the question "Were you satisfied with the cleanliness of your sanitary facilities?" with "no." They had a 3.83-fold increased chance to be unsatisfied with the cleanliness. When asked, "How do you think a doctor would be most likely to respond to your direct feedback on hygiene issues?" women and men responded differently. The male respondents expect a much more positive response from their doctor if they addressed them on hygiene issues. On a negative-positive scale with the values from 1 to 10 , women rated the doctor's reaction with a mean value of 6.06 significantly more negatively than did men, who rated it with an average of 7.43 (mean difference [MD]: 1.364 [95\% CI: 0.451-2.277], $P=0.004$ ). This difference is significant even at the $99 \%$ CI (Table 1). A similar but nonsignificant trend was observed in the evaluation of nurse responses (Figure 2). The performed additional correlation and robustness tests support the presented results.

Other potential influencing factors were also evaluated considering a possible relation with sex. When asked about the length of stay of the patients, it was found that male patients, with an average of 7.19 days, tended to be hospitalized longer than did female patients, with an average of 5.33 days. Since this difference was not significant $(P=0.065)$, we excluded a relation by additionally considering the chisquared, Phi, and Cramér's-V correlation tests. In addition, 
an outlier was identified that was 6.2 times farther away from the interquartile range and was assigned to a male respondent. Therefore, we excluded this male respondent in the analysis of length of stay. The results showed clear statistical insignificance, and this outlier mainly explains the difference (Table 1).

\section{Influence of hygiene competence}

With regard to the extended hygiene competence introduced above, the following proportions were found in the sample: out of 133 respondents, 118 (88.7\%) commented on their occupation. Of these, 15 (11.3\%) had extended hygiene knowledge. The question of current employment was answered by 125 respondents (94.0\%), with $13(9.8 \%)$ having an advanced level of hygiene knowledge. Cross matching occupational training and sex showed that hygiene competence is distributed unequally among the sexes and is disproportionately reducing the number of women more than men (Table 2).

However, considering the described relations between sex and perception of hygiene measures and taking into account professional knowledge, the above-described difference in the perception of disinfectant dispensers does not change; rather, the difference is amplified. These ratios remain significant both in the entrance area (RR: 9.375 [95\% CI: 1.183-74.294], $P=0.013)$ and in the cafeteria area (RR: 6.406 [CI-95: 1.381-29.724], $P=0.015$; Table 3).

Even with the application of the hygiene knowledge filter, the difference in "expectation for response of physicians" not only persists, it even intensifies with averages of 7.53 for men and 5.97 for women (MD: 1.560 [95\% CI 0.473-2.647], $P=0.006$; Table 3).

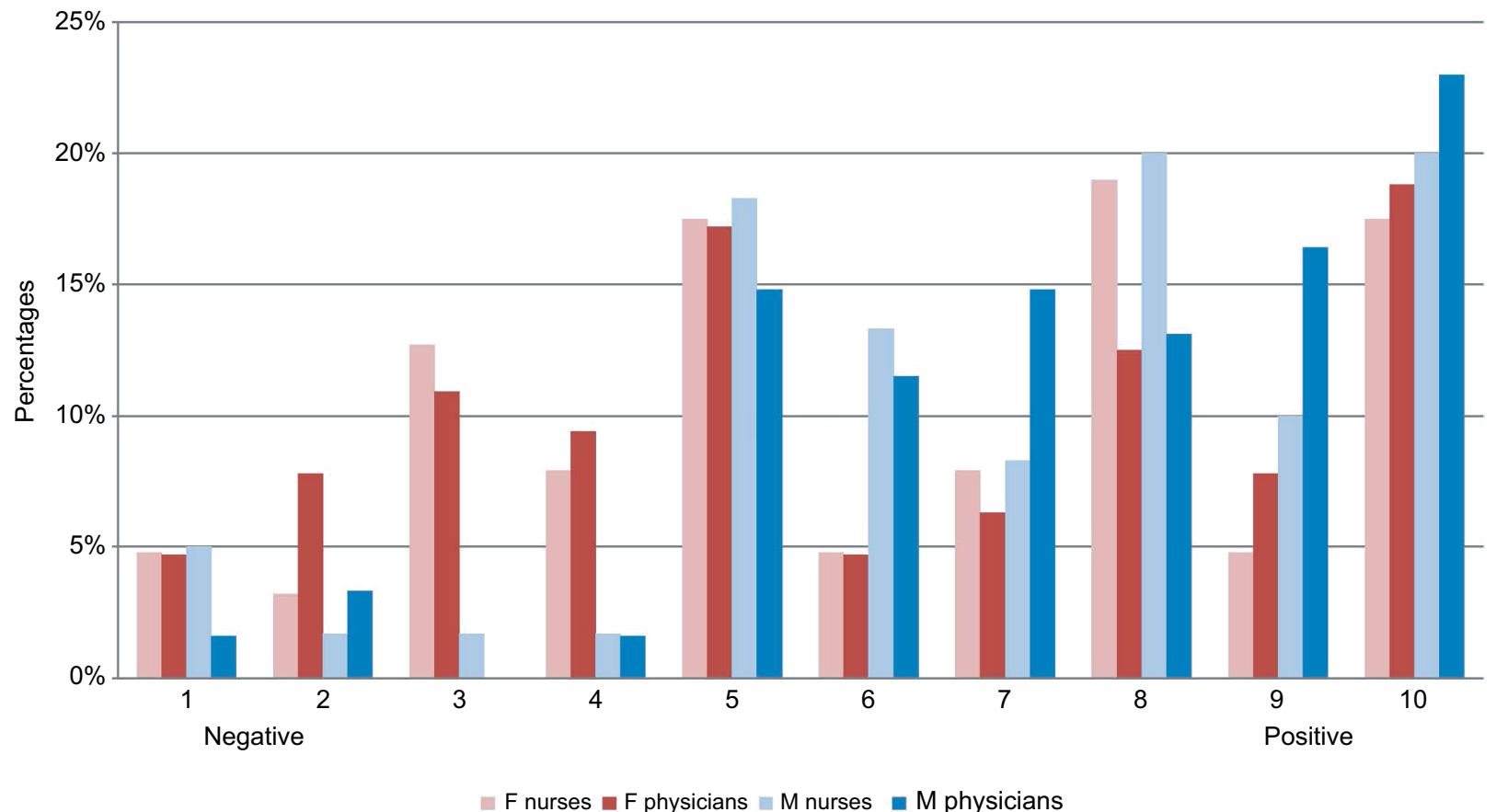

Figure 2 Expected response to hygiene feedback of nurses and physicians by sex (negative I-positive 10).

Notes: Light red=female nurses, bright red=female physicians, light blue=male nurses and bright blue physicians. Number of females $=63 / 64$ and number of males $=60 / 61$. Presentation without filter for hygiene knowledge.

Table 2 Hygiene knowledge of the sample by occupational training/job and sex

\begin{tabular}{|c|c|c|}
\hline & Female $(n=54)$ & Male $(n=63)$ \\
\hline Occupational training with extended hygiene knowledge & $24.1 \%$ & $3.2 \%$ \\
\hline \multirow[t]{2}{*}{ Occupational training without extended hygiene knowledge } & $75.9 \%$ & $96.8 \%$ \\
\hline & Female $(n=6 I)$ & Male $(n=63)$ \\
\hline Job with extended hygiene knowledge & $18.0 \%$ & $3.2 \%$ \\
\hline Job without extended hygiene knowledge & $82.0 \%$ & $96.8 \%$ \\
\hline
\end{tabular}


Table 3 Analysis of the perception and expectation of hygiene-relevant factors by sex with filter "extended hygiene knowledge"

\begin{tabular}{|c|c|c|c|c|c|c|}
\hline & $\mathbf{n}$ & Female (n) & Male (n) & $P$-value & $\begin{array}{l}\text { Risk ratio/mean } \\
\text { difference }\end{array}$ & $95 \% \mathrm{Cl}$ \\
\hline $\begin{array}{l}\text { Perception of } \\
\text { disinfection at entrance }\end{array}$ & 82 & 32 & 50 & 0.013 & 9.375 & I.I83-74.294 \\
\hline $\begin{array}{l}\text { Perception of } \\
\text { disinfection in cafeteria }\end{array}$ & 57 & 16 & 41 & 0.015 & 6.406 & I.38I-29.724 \\
\hline $\begin{array}{l}\text { Expected responses of } \\
\text { physicians }\end{array}$ & 97 & 39 & 58 & 0.006 & 1.560 & $0.473-2.647$ \\
\hline
\end{tabular}

The unilateral restriction of the sample by integrating hygiene competence in the evaluation of cleaning the door handle leads to such a reduction in number of respondents, that the remaining sample is no longer analyzable. The number of women falls by $49.0 \%$, while only $4.2 \%$ of men are eliminated.

\section{Discussion}

In research, a distinction is made between sex as "sex," meaning the chromosomal distribution in cells, and as "gender," the gender determination provided for by society. ${ }^{7,8}$ Both categories are at the same time important preconditions for the way of life and pursuit of a person. The sex of an individual, both biological and sociocultural, is a fundamental imprint manifesting itself in a variety of conditions, rights, states, and predispositions. Sex is determined by the chromosome pairs XX for female and XY for male. Among other things, this causes the hormone balance, which forms female or male anatomies in the fetus and ensures life-long sex-specific characteristics. The gender is socially constructed as identity. This identity is a socially influenced role that, whether male or female, is shaped by traditional, cultural structures, and social ideas..$^{9-11}$ Because of the dynamic nature of the modern discussion about the terms "sex" and "gender," we hereby follow the definition for the term "gender," which is used of a global institution, the WHO. ${ }^{12,13}$

However, the influence of sex or gender in the field of human medicine has so far not been explored intensively. ${ }^{6}$ At this point, we would like to explicitly state the existence of intersex or transgender, such as people with androgen insensitivity or adrenogenital syndrome. ${ }^{6,7}$ However, this study concentrates on the definitional distinction between woman/ female and man/male based on the chromosome pairs XX and $\mathrm{XY}$, the hormonal determination, and dimorphic brain structure as well as the heteronormal gender roles based on the data situation and current research literature.
The data revealed that women are much more sensitive to the lack of disinfectant than men. During the investigation period, there were no dispensers in the direct main entrance area. At the beginning of the intervention phase, a disinfectant dispenser was installed in the waiting area. In the cafeteria area, one device was already set up peripherally. One possible interpretation is provided by the results of evolutionary psychology. Women generally have a spatial localization memory that allows them to better perceive and remember objects in the room, while men have better orientation and pathfinding ability. ${ }^{14-16}$ From this, it can be assumed that the female respondents are more likely to perceive objects such as the disinfectant dispensers or remember that these were not present. This finding does not conflict with the now widely recognized finding that male subjects achieve better results in verifying visio-spatial abilities, especially in mental rotation tasks, while female subjects perform better in language intelligence tests. ${ }^{14,17}$ First, this does not affect the perception and memory of objects and, second, the lead of the male participants in spatial imagination and spatial perception tests by biological differences, such as the average 10\% larger brain size, is currently highly questioned. Boys play mostly with spatially relevant toys more frequently than do girls and thus train this area of brain functions earlier and more intensively. In addition, the assumed intelligence advantages of men are reflected only in isolated ranges of intelligence. It therefore can be assumed that this has more sociological causes with biological outcome than real biological causality. ${ }^{17}$ This further supports the assumption that women are more sensitive to the lack of dispensers and have in fact a different perception of disinfectant dispensers.

Although a disinfectant dispenser was already set up in the cafeteria area, we consider this response to be a better perception of lack of dispensers, because the named dispenser was out of sight. Both dispensers could only be installed in the periphery of the relevant area, because in the zone of cash registers and food distribution as well as in the center of the 
seating area, the space available was too limited. It is therefore to be assumed that not only the number of dispensers must be increased considerably, but they must be visually more obvious installed at spatially dominant sites. One possibility would be to position disinfectant dispensers in signal colors, centrally or "on the way," to appeal to both men and women. Furthermore, the results on cleaning processes and satisfaction with cleanliness point to the facts of the different roles within a society. "Woman" as gender in modern societies is still associated and defined with activities and roles that construct a clear division of responsibilities and work. The topics of cleaning and cleanliness are the responsibility of the traditional activities and professions of women. This leads to a higher number of women in relevant occupations and a greater awareness of shortcomings and activities in these areas. More about this is discussed in the section on the filter hygiene knowledge. Also, the results of the response expectations are very likely to be explained by the different perception of the hierarchical order of gender roles. Here, social identity as a woman leads to a perceived lower status and competence within the social system, resulting in the inhibition of "bottom-to-top" criticism. ${ }^{18-22}$ This circumstance must therefore be included separately in the training of the hospital staff in workshops in order to build up communicative openness, especially toward female patients. In addition, it would be possible to clarify this special fact in the AHOI-information materials or to address these facts directly and in person.

\section{Influence of hygiene competence}

The documentation of advanced hygiene knowledge is necessary to reiterate and exclude possible bias caused by an influence of prior knowledge and sound knowledge on the subject of hygiene in answering the study questions. For this, the occupation of each participant was recorded in order to subsequently categorize these answers dichotomously. Although we are aware that the respondents did not always explicitly learn hygiene as an obligatory topic in their training, it must be assumed that at least disinfection and sterilization are relevant tasks and problems of the jobs mentioned above. The filter for operationalizing prior knowledge shows that there is a gender bias. This fact is also found in the German population. The health and social care industry was dominated by women in all sectors of employment in 2016. Of course, this unequal distribution of genders is also found in other sectors, but here, with a distribution of $77 \%$ women to $23 \%$ men, it is the strongest inequality distribution of all sectors. ${ }^{23}$ It is therefore questionable whether filtering according to occupational prior knowledge of hygiene competence is unimpaired by gender-specific effects. Following this assumption, this bias may even counteract a consideration of the effect of gender.

It is obvious that there are already gender differences in fundamental structures of society, such as employment. While the German health system is one of the fields that is influenced by these differences, other fields of employment and beyond are affected, as well. For example, women tend to work more in workspaces that can be described in terms of customer contact and operation. For example, British women accounted for $84 \%$ of personnel services, and $78 \%$ of administrative and secretarial services in 2001, and 71\% of sales and customer service. ${ }^{17}$ Furthermore, housekeeping is still largely the responsibility of women. In particular, cleaning the home and washing clothes are predominantly done by women ( $20 \%$ men, $49 \%$ women). Women do at least $50 \%$ more housework than their male partners when both work and have a minimum of one child. In 29 European countries, working women in 2005 between the ages of 25 and 39 had three times more unpaid work than did men. ${ }^{17}$ In the concrete subject area, this gender segregation seems to lead to a predisposition for hygiene competence in women, since they are much more likely to be engaged in a related profession or private activity for sociocultural and possibly socio-economic reasons. This leads to a systematic difference between the genders in the perception of and occupation with hygiene and cleanliness. This difference leads to a much greater loss of female respondents in filtering for professional hygiene competence, which in turn removes too substantial and relevant mass of women from the analysis. Consequently, filtering according to hygiene competence only partially operationalizes the influence of previous knowledge and records systematic social structures on a meta-level.

Frequency of patients stays at hospitals and visits to medical practices were evaluated and showed no correlation with sex.

\section{Limitations}

The number of respondents and the survey period were limited in our monocentric survey, which may represent a disparity in the representativeness of all patients across all wards. The survey has provided a sufficient number of cases to answer basic feasibility questions. On the other hand, the dichotomous sex-based identity used here creates a limitation that leaves out people who define themselves differently than the traditional binary separation by sex. That this could be a problem is possibly indicated by the two respondents who did not answer this issue. However, our restriction of sex to female/male is in accordance with the current general research and data collection in the natural sciences. 


\section{Conclusion}

The study showed that AHOI is feasible and is accepted by both sexes. Furthermore, it revealed that sex- and genderspecific differences exist. In particular, the perception of disinfectant dispensers and cleaning processes and quality differs depending on sex or respectively on gender. ${ }^{6}$ As a result, more attention should be paid to the selection and positioning of disinfectant dispensers. Furthermore, we demonstrated that sex- or gender-specific information materials should be adapted and used to target the minimization of hygiene deficits and knowledge gaps. These findings can help to optimize patient involvement and thus increase patient safety.

\section{Acknowledgments}

This study was supported by public grants from the Federal Ministry of Health of the Federal Republic of Germany (grant number ZMVI 1 2516ZPK679). The funding sources played no role in study design and conduct, data collection, analysis or interpretation, writing of the manuscript, or the decision to submit it for publication. The dataset of the represented and analyzed data is available from the corresponding author on reasonable request. We wish to thank several persons and facilities. First of all, we want to thank the participating health care workers, the surgical wards, and their patients. Furthermore, we want to thank Mrs Katja Schulz, Mrs Vivian Henck and Mrs Janina Krafczyk-Korth for their preliminary and executive work for this study. In addition, we want to thank Mrs Maike Schneider for her supportive help in the field of gender and gender policy.

\section{Author contributions}

All authors contributed toward conception, data analysis, drafting and revising the paper; gave final approval of the version to be published; and agree to be accountable for all aspects of the work.

\section{Disclosure}

We disclose grants from the Federal Ministry of Health of the Federal Republic of Germany.

\section{References}

1. Cassini A, Plachouras D, Eckmanns T, et al. Burden of Six HealthcareAssociated Infections on European Population Health: Estimating Incidence-Based Disability-Adjusted Life Years through a Population Prevalence-Based Modelling Study. PLoS Med. 2016;13(10):e1002150.
2. Harrison EM, Ludden C, Brodrick HJ, et al. Transmission of methicillinresistant Staphylococcus aureus in long-term care facilities and their related healthcare networks. Genome Med. 2016;8(1):102.

3. Srigley JA, Furness CD, Baker GR, Gardam M. Quantification of the Hawthorne effect in hand hygiene compliance monitoring using an electronic monitoring system: a retrospective cohort study. BMJ Qual Saf. 2014;23(12):974-980.

4. Barker A, Sethi A, Shulkin E, Caniza R, Zerbel S, Safdar N. Patients' hand hygiene at home predicts their hand hygiene practices in the hospital. Infect Control Hosp Epidemiol. 2014;35(5):585-588.

5. Krafczyk-Korth J, Dittmann K, Heidecke C-D, Kramer A, Hübner N-O. Aktive Einbeziehung von Patienten und Pflegebedürftigen in die Händedesinfektion [Active integration of patients and people in need of care in hand disinfection]. Epid Bull. 2017;18/19:166-168. German.

6. Hornberg C, Pauli A, Wrede B, editors. Medizin - Gesundheit Geschlecht: Gesundheitswissenschaftliche und gendermedizinische Perspektiven [Medicine - Health - Gender: A Health Science Perspective]. In: Medizin - Gesundheit - Geschlecht [Medicine - Health-Gender]. Wiesbaden: Springer VS; 2016:1-21. German.

7. Bale TL, Epperson CN. Sex as a Biological Variable: Who, What, When, Why, and How. Neuropsychopharmacology. 2017;42(2): 386-396.

8. Miller LR, Marks C, Becker JB, et al. Considering sex as a biological variable in preclinical research. FASEB J. 2017;31(1):29-34.

9. Lohff B, Rieder A. Einleitung: Gender Medizin — eine neue Disziplin? In: Rieder A, Lohff B, editors. Gender Medizin. Wien/Vienna: Springer VS; 2008: 1-12. German.

10. Warnke G. Debating Sex and Gender. New York: Oxford University Press, Inc; 2011.

11. Becker JB, McClellan ML, Glover Reed B. Sex differences, gender and addiction. J Neurosci Res. 2017;95(1-2):136-147.

12. World Health Organization [webpage on Internet]. Gender, equity and human rights. Glossary of terms and tools. Available from: http:// www.who.int/gender-equity-rights/knowledge/glossary/en/. Accessed November 5, 2018.

13. Broughton DE, Brannigan RE, Omurtag KR. Sex and gender: you should know the difference. Fertil Steril. 2017;107(6):1294-1295.

14. Silverman I, Choi J. Locating Places. In: Buss DM, editor. The Handbook of Evolutionary Psychology. Hoboken, NJ: John Wiley \& Sons Inc; 2005:177-199.

15. Silverman I, Choi J, Peters M. The hunter-gatherer theory of sex differences in spatial abilities: data from 40 countries. Arch Sex Behav. 2007;36(2):261-268.

16. Bettis T, Jacobs LF. Sex differences in object recognition are modulated by object similarity. Behav Brain Res. 2012;233(2):288-292.

17. Borchers AT, Gershwin ME. Sociological differences between women and men: implications for autoimmunity. Autoimmun Rev. 2012;11(6-7):A413-A421.

18. Klinger C. Die Ordnung der Geschlechter und die Ambivalenz der Moderne [The order of the sexes and the ambivalence of the modern age]. In: Becker S, Kleinschmidt G, Nord I, Schneider-Ludorff G, editors. Das Geschlecht der Zukunft. Zwischen Frauenemanzipation und Geschlechtervielfalt [The Gender of the Future. Between women's emancipation and gender diversity]. Stuttgart: Kohlhammer; 2000. German.

19. Carli LL, Eagly AH. Gender, Hierarchy, and Leadership: An Introduction. J Soc Issues. 2001;57(4):629-636.

20. Funder M. Die Mainstreaming-Organisationsforschung-Reflexionen aus einer Genderperspektive [Mainstreaming Organizational Research - Reflections from a Gender Perspective]. In: Funder M, editor. Gender Cage-revisited: Handuch zur Organisations- und Geschlechterforschung [Gender cage - revisited: Handbook on Organizational and Gender Studies]. Baden-Baden: Nomos; 2014: 29-57. German. 
21. Rudman LA, Moss-Racusin CA, Phelan JE, Nauts S. Status incongruity and backlash effects: Defending the gender hierarchy motivates prejudice against female leaders. J Exp Soc Psychol. 2012;48(1):165-179.

22. Bublitz H. Geschlecht [Gender]. In: Korte H, Schäfer B, editors. Einführung in Hauptbegriffe der Soziologie [Introduction to main concepts of sociology]. 9th ed. Wiesbaden: Springer VS; 2016:101-125.
23. Bundesagentur für Arbeit, Statistik/Arbeitsmarktberichterstattung [Federal Employment Agency, Department for Statistics/Labor Market Reporting]. Die Arbeitsmarktsituation von Frauen und Männern 2016 [The labor market situation of women and men 2016]. In: Berichte: Blickpunkt Arbeitsmarkt [Reports: Focus Labour Market]. Nürnberg: 2017. German.

\section{Publish your work in this journal}

Infection and Drug Resistance is an international, peer-reviewed openaccess journal that focuses on the optimal treatment of infection (bacterial, fungal and viral) and the development and institution of preventive strategies to minimize the development and spread of resistance. The journal is specifically concerned with the epidemiology of antibiotic

\section{Dovepress}

resistance and the mechanisms of resistance development and diffusion in both hospitals and the community. The manuscript management system is completely online and includes a very quick and fair peerreview system, which is all easy to use. Visit http://www.dovepress.com/ testimonials.php to read real quotes from published authors.

Submit your manuscript here: https://www.dovepress.com/infection-and-drug-resistance-journal 